\title{
Safeguard or mollycoddle? Medical student placements in Aboriginal communities
}

TO THE EDITOR: We read with interest the article by Patel and colleagues, ${ }^{1}$ which suggests a high rate of critical adverse events occurring for medical students undertaking remote placements in the Northern Territory. We note also that there is significant potential for over- or under-reporting because of the incompleteness of useable documentation in their sample. Regardless, the reported figure of one-sixth of students experiencing a "critical incident" during their placement is concerning. 
In answer to the question in the title of Patel et al's article "Safeguard or mollycoddle?" — the answer is surely neither. There is obvious benefit for students in being removed from their personal, cultural, geographical and clinical comfort zones. After all, challenging and evaluating one's preconceptions and personal boundaries is essential for personal and professional development. However, it is vital that this is done in a safe and well supported manner, such that both the student and the community into which he or she is placed benefit from the experience.

As noted by Patel et al, there is evidence from the United Kingdom that structured placements that are regularly evaluated, adequately planned and firmly grounded in clinical ethics are able to maximise the placement experience for both students and communities. ${ }^{2}$ In our minds, the key to quality in clinical placements is excellent administrative support and clinical supervision that is appropriate for the level of the student.

Recently, there has been a concerted push in medical training to encourage students to gain experience in rural and Aboriginal communities. This is generally well received by Australian medical students. In light of increasing student numbers, it is likely that these alternative clinical training environments will see an increase in student traffic in the coming years. The article by Patel et $\mathrm{al}^{1}$ has highlighted that not all experiences in these settings are positive. Due to persisting rural workforce shortages, we are concerned that students who are unwilling and potentially unsuitable to undertake remote placements may be forced to do so through their medical programs or bonded medical places.

We strongly urge the providers of placements and those who fund them to critically evaluate their current practices surrounding clinical placement planning and support. Most importantly, adequate supervision, matched to the individual attributes of the student, should be an absolute requisite for any placement.

\author{
Andrew D Webster Vice-President External \\ Robert D Marshall President \\ Lee J Fairhead Public Relations Officer \\ Trent Little Rural and Indigenous Officer \\ Falk Reinholz Community and Wellbeing Officer \\ National Executive, Australian Medical Students' \\ Association, Canberra, ACT. \\ vpe@amsa.org.au \\ Competing interests: No relevant disclosures. \\ doi: 10.5694/mjall.10997 \\ 1 Patel A, Underwood P, Nguyen HT, Vigants M. \\ Safeguard or mollycoddle? An exploratory study \\ describing potentially harmful incidents during \\ medical student placements in Aboriginal \\ communities in Central Australia. Med J Aust \\ 2011; 194: 497-500. \\ 2 Dowell J, Merrylees N. Electives: isn't it time for \\ a change? Med Educ 2009; 43: 121-126.
}

